CB.User studies

\title{
NECESSIDADES DE INFORMAÇÃO DO GÊNERO MULHER NO DISTRITO FEDERAL, BRASIL: RESULTADOS DE UM SURVEY
}

WOMEN GENDER INFORMATION NEEDS IN DISTRITO

FEDERAL, BRAZIL: A SURVEY RESULTS

\author{
Rita de Cássia do Vale Caribé ${ }^{1}$ \\ Alejandra Aguilar Pinto ${ }^{2}$ \\ Fabiene Castelo Branco Diogenes ${ }^{3}$
}

\begin{abstract}
RESUMO
Estudo insere-se na área de estudo de usuários, relata os resultados de um survey, realizado no Distrito Federal (DF), Brasil, com o objetivo de identificar as necessidades e o uso de informação pelas mulheres, tendo utilizado uma amostra aleatória de 37 entrevistas estruturadas. Inclui breve revisão de literatura sobre estudos de usuários com o objetivo de identificar as necessidades e uso da informação por diferentes categorias de indivíduos; apresenta a evolução dos estudos de usuários em termos metodológicos e de abordagem quantitativa e qualitativa; e estudos relacionados à necessidade e uso de informação do gênero mulher. Nesta pesquisa foram identificados os graus de importância de alguns temas, as fontes e instrumentos que interessam à mulher do DF e a gradação de frequência do uso, bem como, analisada a relação dessas fontes de preferência com o perfil de escolaridade, idade e renda.
\end{abstract}

PALAVRAS-CHAVE: Estudo de usuário. Necessidade de informação. Gênero mulher.

\begin{abstract}
This study may be considered an information user needs study. It reports results of a survey conducted in Distrito Federal (DF), Brazil. Its objective was identifying the information needs and use of women, and was used a random sample of 37 interviews structured. Includes brief literature review on user studies with the goal of identifying the needs and use of information by different individuals categories; shows the evolution of user studies of quantitative and qualitative methodology and approach; and the need and use of information from the woman gender studies. In this research the importance degrees of some topics, sources and instruments that are interested to the wife of DF and gradation of frequency of use were identified, were analyzed the relationship of these sources preferably with the profile of education, age and income.
\end{abstract}

KEYWORDS: User information needs. User studies. Woman gender.

\footnotetext{
1 Professora Adjunta da Faculdade de Ciência da Informação da Universidade de Brasília. E-mail: rita.caribe@gmail.com

${ }^{2}$ Doutora Ciência da Informação pela Universidade de Brasília. E-mail: ale.cinf@ gmail.com

${ }^{3}$ Instituto Brasileiro de Informação em Ciência e Tecnologia (IBICT). E-mail: fabienecastelo@gmail.com

Recebido em: 15/06/2014 - Aceito em: 12/02/2015
} 


\section{INTRODUÇÃO}

Este estudo insere-se na área de estudo de usuários do gênero mulher e relata os resultados de um survey, realizado no Distrito Federal (DF), Brasil, com o objetivo de identificar as necessidades e o uso de informação pelas mulheres. Para a coleta de dados foi utilizada a entrevista estruturada aplicada a uma amostra aleatória de 37 entrevistadas residentes no DF. Analisou-se a evolução dos estudos e conceitos sobre o gênero mulher a partir da década de 1970; os estudos sobre necessidades de informação da mulher; a evolução dos estudos de usuários em termos metodológicos e de abordagem quantitativa e qualitativa. Como resultados desta pesquisa, foram identificados os graus de importância de alguns temas, as fontes e instrumentos que interessam à mulher do DF e a gradação de frequência do uso, bem como, analisada a relação dessas fontes de preferência com o perfil de escolaridade, idade e renda.

\section{GÊNERO MULHER E A INFORMAÇÃO}

O termo gênero passou a ser utilizado, partir da década de 1970, para teorizar a questão da diferença sexual, tendo sido utilizado, inicialmente, pelas feministas americanas. Soihet (2003), com base em Joan Scott, argumenta que no uso, o gênero é apenas um conceito associado ao estudo das coisas relativas às mulheres, e que esses estudos não têm força de análise suficiente para interrogar e mudar os paradigmas históricos existentes. É necessária a análise, não só da relação entre as experiências masculinas e femininas no passado, mas também da ligação entre a história do passado e as práticas atuais.

Os primeiros estudos de gênero, realizados entre os anos de 1960 e 1970, colocavam a mulher como sujeito-objeto, porém com o passar do tempo ganharam espaço e consistência a partir das abordagens teóricas da sociologia, história, literatura, educação dentre outros, evoluindo o conceito de gênero para estar mais ligado a uma construção social do sujeito masculino e feminino (LOURO, 1996, p.15).

Portanto, o conceito de gênero

[...] diz respeito à dimensão social construída do masculino e do feminino, que transformou sexo, fator biológico, num fator social/cultural. A construção desse conceito representa um esforço de entender a dinâmica das relações hierárquicas e desiguais de gênero, ou seu conteúdo mutável e conjuntural, que pressupõe mudanças e permanências, desconstrução, reconstrução de práticas, comportamentos, normas, representações e mentalidades (ARAUJO, 1998, p. 9596).

Autores como Eggert (2001) e Velho e Prochazka (2003) consideram que ainda que a mulher tenha conquistado espaço no mundo acadêmico, político, profissional, educacional esta ainda não conseguiu a igualdade de direitos ou a paridade entre os gêneros.

O Brasil, por exemplo, embora tenha como princípio constitucional e garantia jurisdicional, a equidade de gênero - artigo 5º inciso I da Constituição Federal, 1988 - há, de 
acordo com Simioni (2003), um descompasso entre a declaração de tal direito fundamental e as práticas sociais, entre elas, a jurídica, notadamente no que tange à família, à reprodução e à sexualidade.

Desse modo, um dos papéis do Estado seria promover uma readequação do papel da mulher na sociedade como sugere um artigo do número especial dedicado à mulher na ciência da revista ComCiência (2003).

Dentro desse contexto, trabalhos de pesquisa sobre mulher no âmbito da Ciência da Informação são defendidos por McCarthy (1984 apud EGGERT, 1992) com o argumento de que o mundo vive a Era da Informação e que, de acordo com Lambert (1991 apud EGGERT, 1992), há um contexto mais amplo para se trabalhar com mulheres no nível mundial, continental e nacional.

Segundo Eggert (1992, p. 13) é necessário mobilizar as mulheres contra a ignorância, o analfabetismo e os preconceitos milenares, o que pode significar um passo à frente para renovação do País. Neste sentido, a Ciência da Informação e a Biblioteconomia deveriam se comprometer com as questões da ação das mulheres por meio das bibliotecas e centros de informação contribuindo para o processo de mudança em todos os segmentos e classes sociais.

A falta de informação se constitui em fator de discriminação e exclusão da mulher e, embora estejamos na dita "sociedade da informação" ainda existem países ricos e pobres de informação, dos quais as mulheres representam uma parte significativa. A falta de conhecimento para o uso das novas tecnologias de informação e comunicação (TIC) se constitui em outro fator de discriminação e contribui para aumentar a desigualdade entre homens e mulheres. Conforme constatação dos grupos feministas que participaram da Cúpula Mundial da Sociedade da Informação, na Tunísia se a exclusão digital tivesse um rosto, teria o rosto de mulher (Acesso a informação, 2001; DETONI, 2007).

Um dos instrumentos necessários para alcançar essa igualdade tão desejada está relacionado à informação, que, como fator preponderante para o crescimento dos povos na sociedade da informação, constitui-se em um novo modo de desenvolvimento da sociedade que regula as relações entre os seus vários segmentos e torna o acesso à informação um dos principais argumentos de uma sociedade global que, segundo Borgman (2001), tem como premissa a conexão de uma rede de computadores e telecomunicações e como promessa uma sociedade de cooperação com oportunidades igualitárias.

As mudanças no contexto mundial e nacional vêm exigindo, cada vez mais, atenção na identificação das necessidades de informação dos usuários para o planejamento de serviços de informação. Dentre os estudos de gênero estão aqueles que voltam a atenção para entender as necessidade e uso da informação pela mulher. 


\section{ESTUDOS DE USUÁRIOS: UMA BREVE REVISÃO DE LITERATURA}

A literatura sobre estudos de usuários no mundo tem crescido. Lin e Garvey (1972 apud BAPTISTA; CUNHA, 2007) em artigo de revisão publicado no Annual Review of Information Science and Technology (ARIST) mencionaram que a temática estava em grande atividade e que se tinha transformado em um fenômeno internacional. Wilson (2006) compartilha dessa visão quando afirma que, além da área de recuperação da informação, nenhuma outra tem desenvolvido tantos estudos como a área de estudo de usuários e dentro desta a de necessidades de informação.

Tradicionalmente, os estudos de usuários estavam voltados para sistemas de informação e usavam métodos quantitativos para mensurar o quanto e como os usuários utilizavam estes sistemas, suas preferências e fontes (STUMP, 2007).

Na década de 1960 os estudos de usuários em bibliotecas estavam direcionados a identificar a frequência de outros comportamentos de forma puramente quantitativa. $\mathrm{Na}$ década de 1970 os estudos estavam direcionados a identificar como a informação era obtida e usada (BAPTISTA; CUNHA, 2007). Na década de 1980, segundo Pinheiro (1982, apud BAPTISTA; CUNHA, 2007) os estudos de usuários tinham o objetivo de subsidiar o planejamento dos serviços e sistemas de informação que fossem capazes de satisfazer às necessidades, porém os resultados não foram alcançados devido à complexidade de determinar os estudos e comportamento dos usuários. Ainda em 1992, conforme análise de Lima (apud BAPTISTA; CUNHA, 2007), esses estudos estavam voltados muito mais para o funcionamento das unidades de informação.

Passou-se, então, da fase quantitativa para a fase qualitativa. Os estudos passaram a descrever comportamentos e a utilizar vários métodos de coleta especialmente qualitativos (BAPTISTA; CUNHA, 2007; STUMP, 2007). Esses estudos trouxeram um nível de entendimento em vários contextos dos estudos de usuários, mas também dificuldades em integrar os diversos resultados (WANG, 1999, p. 83).

Algumas revisões de literatura têm mostrado os problemas críticos e generalizáveis no campo do estudo de necessidades e uso da informação como a falta de uniformidade conceitual nas pesquisas; faltam definições e pressupostos claros para focalizar variáveis e gerar questões de pesquisa; ausência de metodologias específicas, abrangentes e com rigor científico, de definições coerentes para vários conceitos pertinentes a estudos de usuários (SILVA; FERREIRA; BORGES, 2002).

Com o objetivo de tornar mais clara a base teórica dos estudos de usuários Wilson (2006) discute alguns conceitos e propõe a base para a teoria de motivações para o comportamento de busca de informação defendendo uma visão holística do usuário o que direciona as buscas de informação, não somente para fins cognitivos, mas para as necessidades dos usuários no seu aspecto de trabalho e social, os quais criam motivações para a busca da informação, para ajudar a satisfazer necessidades afetivas. 
Esta mudança no foco da pesquisa de fontes e sistemas de informação usados pelo usuário para investigar o papel da informação na sua vida diária, no cenário de trabalho ou social repercute na utilização de métodos de estudos de necessidades de informação que passam a utilizar, intensamente, os métodos qualitativos (WANG, 1999; WILSON; 2006). A pesquisa qualitativa foca sua atenção nas causas da reação dos usuários da informação e na resolução do seu problema informacional (BAPTISTA; CUNHA, 2007).

\section{NECESSIDADES DE INFORMAÇÃO DO GÊNERO MULHER}

Pesquisas realizadas em bases de dados especializadas em Ciência da Informação sobre o assunto gênero, focado principalmente nos temas mulheres, informação, uso e necessidades não teve como resultado uma grande quantidade de itens recuperados.

Por meio da base Library Information Science Abstracts (LISA), no contexto internacional foram identificados poucos estudos relacionados à necessidade de informação das mulheres. Várias pesquisas de mulheres em países em vias de desenvolvimento (principalmente africanos) destacam-se em situações de migração, de trabalho rural, no serviço público, setor informal etc.

Um dos primeiros estudos foi de Gundara (1981) sobre as necessidades de informação das mulheres indianas e paquistanesas no Reino Unido, considerando o papel da biblioteca como um serviço de informação multi-propósito.

Em 1987, Fairer-Wessels pesquisou as necessidades de informação de mulheres negras sul africanas, residentes nas áreas urbanas com situação de desvantagem econômica; em 1990 pesquisou sobre o valor dos serviços de informação comunitária para as mulheres urbanas negras na África do Sul considerando as necessidades especificas das mulheres negras em Mamelodi, Pretoria (FAIRER-WESSELS, 1990).

$\mathrm{Na}$ área rural, Nwagha (1992) realizou o estudo sobre as necessidades de informação da mulher rural na Nigéria, revelando que as mulheres rurais, na sua maioria analfabeta, ignoram os modernos métodos de melhoria da produção agrícola e outras formas de autodesenvolvimento, recomendou disseminação da informação como um meio efetivo de desenvolvimento rural.

Um estudo sobre a mulher na agricultura realizado por Oladokun (1994) revelou que suas necessidades de informação estão sendo satisfeitas, por canais formais e informais. Kiondo (1999) investigou o problema do acesso à informação pelas mulheres rurais nos países em desenvolvimento, enfocando três distritos da região de Tanga na Tanzânia, observou que as relações de gênero patriarcais na maioria das sociedades rurais provocam desigualdades entre grupos de gênero e o acesso à informação.

Outro estudo relativo à mulher na área rural, realizado por Mooko (2005), investigou as necessidades e o comportamento na procura de informação das mulheres rurais residentes em três vilas não urbanas de Botsuana. As situações familiares que as levaram a procurar 
informação incluíram saúde, agricultura, emprego, violência familiar e necessidades básicas para a família.

Tendo observado que o setor informal estava em forte crescimento em Uganda, e incorporava muitas mulheres, Ikoja-Odongo (2002) estudou e descreveu suas necessidades e estratégias de procura de informação, assim como as características desse setor de emprego, as fontes, os canais que eram utilizados para ter acesso à informação e suas dificuldades.

Mabawonku (2006) realizou estudo com o objetivo de identificar as atividades relacionadas às necessidades e acesso à informação em ambientes públicos. Como técnica de coleta de dados usou o questionário e a observação de 158 mulheres na área pública. A maioria das necessidades de informação estava relacionada ao governo, educação, religião, família e matérias domésticas. Jornais, revistas, newsletters, colegas, conversas foram também consideradas fontes de informação. As fontes eletrônicas, como a Internet não estavam amplamente disponíveis, apesar do entusiasmo demonstrado quanto ao seu uso.

Em seu estudo Whitt (1993) descreve uma pesquisa realizada junto a 141 lésbicas numa área metropolitana da Carolina do Norte com o objetivo de medir as necessidades de informação desse grupo, o uso e a satisfação com relação à informação recebida. Várias recomendações foram feitas para melhorar os serviços bibliotecários para esta população.

Estudos mais amplos das mulheres considerando-as como um segmento, setor, minoria da sociedade também foram identificados. Um deles é o de Stokes (1987) que enfoca sobre os centros comunitários, suas atividades com ênfase especial nas necessidades de grupos minoritários, tais como pequenos grupos, grupos emergentes, grupos de mulheres negras e sem recursos. A classe de posição dos grupos é o fator decisivo no acesso e uso da informação. Destaca que todas as comunidades e organizações voluntárias necessitam ter acesso a uma ampla classe de oportunidades de treinamento e que os bibliotecários têm a capacidade de reunir e disseminar informação e treinar os usuários.

O trabalho de Glass (1990) traz uma contribuição para uma edição dedicada aos periódicos e serviços de referência. As necessidades de informação das mulheres como minoria têm recebido pouca atenção. Todos os grupos étnicos compartilham a necessidade por materiais educacionais imparciais.

Durante os anos 1990 e começo do século XXI surgem novos temas relacionados com as necessidades de informação da mulher. Heijs (1990) realizou estudo de três bibliotecas públicas da Holanda e de suas coleções sobre a temática das mulheres, constatou que tais materiais estavam pobremente representados nas coleções; que o material registrado nos catálogos era difícil de localizar nas coleções; que todas as bibliotecas tinham folders ou panfletos de recortes sobre o tema, porém indexados inadequadamente; e que o staff da biblioteca estava sempre ocupado para assistir ao usuário na sua busca de informação.

Outro trabalho relacionado ao anterior é o de Van Westrum e Schade (1990) sobre o desenvolvimento de coleções de bibliotecas para atender às necessidades de informação da 
mulher. Na Holanda, os grupos de apoio às mulheres frequentemente se queixam de dificuldades de localizar informação nas bibliotecas públicas. Para testar a validade destas reclamações um levantamento foi feito nas coleções de nove bibliotecas públicas usando listas de leituras compiladas pela International Information Centre an Archive for the Womens's Movement. O resultado preliminar do estudo mostrou que as bibliotecas têm adquirido só uma pouca proporção dos títulos listados.

Quanto ao uso de bibliotecas pelas mulheres, a pesquisa de King (1995) analisou que o estudo das necessidades de informação das mulheres, e dos assuntos/matérias mais tradicionais das mulheres são negligenciados. Observou que quando esses assuntos são estudados, é realizado a partir do ponto de vista do desenvolvimento das coleções, não a partir das necessidades de informação das mulheres. Nesse contexto realizou uma revisão de cinco categorias de "assuntos das mulheres": áreas tradicionais como a costura; informação relativa a mudanças na vida como retorno ao trabalho, saúde da mulher e família.

O trabalho realizado por Foster (1999) fornece exemplos da interação entre sistemas de informação e mulheres no campo de trabalho dos serviços sociais. A forma em que os sistemas de informação são considerados; a maneira como as mulheres desenvolvem e operam esses serviços de informação.

Quanto às necessidades de informação de portadoras de HIV há o trabalho de Huber e Cruz (2000) que apresenta os resultados de um questionário aplicado a 205 HIV positivos homens e mulheres que forneceram apoio para os diferentes tipos da procura de informação.

No âmbito da União Europeia foi identificado o estudo de Marcella (2001), que pesquisou sobre as necessidades de informação das mulheres do Reino Unido e suas formas de comportamento na procura de informação em relação à União Europeia. $\mathrm{O}$ resultado mostrou que as mulheres valorizam a informação e usam uma ampla classe de categorias de informação em relação à educação e sua vida profissional e pessoal.

No Brasil merecem destaque o estudo realizado por Nascimento (2003) e a pesquisa de mestrado de Eggert (1992).

O estudo realizado por Nascimento (2003) teve como objetivo identificar as necessidades de informação da mulher catarinense e as formas de busca adotadas. Utilizou o questionário seguido de entrevista, de forma a permitir que as pessoas pesquisadas pudessem se manifestar livremente. Os resultados indicaram que a informação pode ajudar a diminuir a discriminação e as diferenças sociais, sendo que do total da amostra da pesquisa apenas $13 \%$ afirmaram conhecer bibliotecas, bases de dados ou páginas na internet que tratam de assuntos sobre gênero, porém não souberam identificar essas fontes que afirmaram conhecer.

A dissertação de mestrado de Eggert (1994) consiste em um dos poucos estudos sobre a mulher na literatura brasileira. A pesquisa foi desenvolvida entre 1991-92, na periferia de Belo Horizonte, Minas Gerais e buscou identificar as fontes de informação utilizadas por 
donas de casa. A técnica de coleta de dados foi a História de Vida que possibilita revelação do cotidiano e a rememoração em quatorze mulheres mães e donas de casa.

Os dados mostraram que por meio de contatos com revistas populares, TV e membros da família, as mulheres receberam constantemente a ideia da mulher submissa. Isso indicou a importância das bibliotecas públicas na identificação das necessidades deste grupo, tornando acessível outros tipos de materiais para "atacar" os gêneros estereotipados.

O grupo pesquisado citou um total de 115 fontes de informação de natureza impressa, audiovisual e oral, sendo as fontes de natureza impressa as mais citadas pelas mulheres que estão no mercado informal de trabalho. Essas mulheres citaram $66,6 \%$ do total das fontes impressas, enquanto o subgrupo de donas de casa citou 21,4\%. O subgrupo das mulheres donas de casa, inseridas no mercado de trabalho formal, citou o menor número desse tipo de fonte de informação, 12,0\%, alegando que a dupla jornada de trabalho e as obrigações domésticas restringem o tempo para atividades de leitura.

A preferência das mulheres donas de casa no que tange às fontes impressas, concentra-se em revistas e romances populares. As revistas de cunho informativo foram as mais citadas, depois as sentimentais e em seguida as eróticas. A soma das revistas sentimentais de $35 \%$ e os romances populares de $19 \%$ traduzem um caráter qualitativo bastante significativo para este grupo de mulheres. A pesquisa mostrou que as fontes orais são de dupla importância para as camadas populares de baixo poder aquisitivo (EGGERT, 1992).

\section{METODOLOGIA}

\subsection{Abordagens e métodos de pesquisa em estudos de usuários}

As duas abordagens metodológicas mais correntes - os métodos de pesquisa quantitativo e qualitativo - são discutidas por Minayo e Sancho (1993). Segundo esses autores o método quantitativo lida com indicadores e tendências observáveis, com grandes aglomerados de dados, de conjuntos demográficos, por exemplo, classificando-os e tornandoos inteligíveis por meio de variáveis. A questão fundamental é decidir que espécies de dados matemáticos são relevantes para determinados problemas, que limitações estão impostas e como os métodos quantitativos podem ser ampliados e generalizados. Deve ser exercitada a habilidade no julgamento de quais fatores são relevantes, ou pelo menos aproximadamente relevantes, para um determinado problema (MINAYO; SANCHO, 1993).

O método qualitativo trabalha com valores, crenças, representações, hábitos, atitudes e opiniões, aprofunda a complexidade dos fenômenos, fatos e processos particulares e específicos de grupos mais ou menos delimitados em extensão e capazes de serem abrangidos intensamente. $\mathrm{O}$ material principal da investigação qualitativa é a palavra que expressa a fala cotidiana, seja nas relações afetivas e técnicas, seja nos discursos intelectuais, burocráticos e políticos (MINAYO; SANCHO, 1993). 
$\mathrm{Na}$ coleta de dados em estudos de usuários os métodos mais utilizados também estão relacionados às abordagens quantitativas e qualitativas (BAPTISTA; CUNHA, 2007; SILVA; FERREIRA; BORGES, 2002; WANG, 1999).

Observa-se na literatura que as técnicas de coleta de dados para estudos de usuários são os questionários, as entrevistas e a observação com algumas variâncias. Na visão de Baptista e Cunha (2007) os questionários são utilizados em estudos quantitativos e a entrevista e a observação em estudos qualitativos destacando-se o questionário como uma das técnicas mais utilizadas seguindo-se o da entrevista. A análise de conteúdo é outra técnica apropriada para mensurar a legibilidade de um texto e analisar questões relacionadas com atitudes, interesses e valores culturais de um grupo. Para Wang (1999) são quatro as principais técnicas para a pesquisa de comportamento: questionário, entrevista, observação e experimento. São utilizados nas áreas de estudo de uso e necessidades de informação, na busca de informação, no estudo de julgamento de relevância, na busca online, nas interações entre o sistema e o homem, e na transação da referência (observado em campo experimental).

Os avanços na área de estudos de usuários mostram que podem ser feitos estudos quantitativos e qualitativos mais sofisticados; apropriados - teórica e instrumentalmente para o desenvolvimento de sistemas baseados nas especificidades dos usuários finais. Mostram, também, que os métodos quantitativos e qualitativos usados em estudos de usuários são vistos por muitos autores como abordagens complementares. É importante observar que o problema que se tenta resolver no estudo ou pesquisa é que irá determinar a metodologia; o pesquisador deverá saber escolher os métodos mais adequados para a coleta dos dados; e o conhecimento profundo do método a ser adotado bem como o preparo do pesquisador constituem-se em fatores-chave para o sucesso do estudo (BAPTISTA; CUNHA, 2007; MINAYO; SANCHO, 1993; WANG, 1999).

\subsection{Método utilizado no levantamento das necessidades da mulher do DF}

A entrevista como survey method - método de levantamento - baseado na percepção dos usuários tem sido bastante utilizada para estudar uso e necessidades de informação. Caracteriza-se principalmente pela interação entre o entrevistador e o entrevistado e é usada como técnica de levantamento de dados alternativa para administrar o questionário para melhorar a qualidade (WANG, 1999). Com base nesta observação optou-se pela técnica da entrevista estruturada, para identificação das necessidades da mulher no Distrito Federal com enfoque quantitativo uma vez que as perguntas são fechadas e os resultados são apresentados em formato estatístico.

Neste trabalho não foi possível utilizar a técnica de entrevista de forma complementar a outro método, nem considerar uma abordagem qualitativa devido à limitação de tempo para aplicação da entrevista que não propiciou cruzamento e relações aprofundadas. É necessário ressaltar que a elaboração do instrumento de coleta e a aplicação do pré-teste da entrevista foi um importante exercício para se perceber algumas das dificuldades e cuidados que se deve tomar na realização de estudos à semelhança deste. Ficou evidente que a identificação dos 
itens que compõem o instrumento de coleta de dados deve ter relação direta com os objetivos propostos; que as construções claras das questões do instrumento de coleta e o pré-teste contribuem de modo decisivo para a confiabilidade dos resultados; igualmente a aplicação da entrevista permitiu que se percebesse de que a maneira de abordagem pode influir na reação de interesse dos usuários em aceitarem ser entrevistados.

Esta pesquisa foi realizada em 2011. O universo desta pesquisa integrou mulheres do Distrito Federal, tendo sido considerada uma amostra de 37 entrevistas em diversos locais, que foram escolhidos por serem locais de grande convergência de pessoas com diferentes níveis sociais, econômicos e culturais. A Feira do Guará e a Feira da Torre de TV foram visitadas no final de semana, quando um quantitativo maior de pessoas as visita compras e turismo. O terminal do metrô, Universidade de Brasília foram visitados durante a semana e reuniões de família. Esses locais foram escolhidos com o objetivo de buscar atingir a um público o mais diversificado possível, ou seja, pessoas com diferentes idades, ocupações, poder aquisitivo, nível educacional. Devido à limitação de recursos, as entrevistas foram realizadas pelas próprias pesquisadoras em um final de semana e em dois dias durante a semana.

\subsection{Etapas de elaboração e realização da entrevista}

O instrumento de coleta de dados foi elaborado a partir da identificação de itens e temas adotados nos estudos realizados por Nascimento (2003) e por Lima (2007).

O roteiro da entrevista foi estruturado em duas grandes categorias: 1) dados pessoais e 2) necessidades e uso da informação. Na categoria dados pessoais foram consideradas as variáveis: faixa etária, local de residência, renda familiar, nível de escolaridade, tipo de trabalho. Na categoria necessidades e uso da informação: temas sobre direitos do cidadão; atualidades; lazer e cultura, crescimento pessoal; fontes de leitura; instrumentos utilizados; local de acesso à Internet; local onde encontrou a informação que precisou; dificuldades encontradas quando precisou de informação.

O pré-teste foi realizado com duas pessoas do gênero mulher: uma com formação de segundo grau e a outra com curso de graduação. As perguntas sobre as categorias dados pessoais foram bem entendida por ambas. A categoria de necessidades de uso da informação no item direito do cidadão mostrou que havia necessidade de explicar qual o foco da pergunta explicitando que se tratava de informação relacionada com ações e propostas de governo e legislação que mostravam os direitos do cidadão nas áreas inquiridas. A gradação de frequência nessa questão relacionada aos temas dos tipos de informação que procura foi alterada em função das observações das duas entrevistadas no pré-teste. $\mathrm{O}$ item referente às principais dificuldades para encontrar informação também foi reformulado em seus vários subitens. 
$\mathrm{Na}$ aplicação da entrevista observou-se que ao abordar pessoas em locais públicos aquelas que estavam quietas em algum lugar ou caminhando sem muita pressa foram mais receptivas a participar da entrevista.

\section{ANÁLISE DOS DADOS E RESULTADOS}

Os dados obtidos por meio das 37 entrevistas realizadas são referentes a: $24 \%$ das mulheres na faixa etária maior ou igual a 50 anos seguido das mulheres de 24 a 29 anos e 30 a 35 representando $22 \%$ respectivamente. Estas três faixas etárias representam $68 \%$ do universo entrevistado. As faixas de 16 a 18 anos, 36 a 40 anos, 41 a 45 anos representam cada uma $8 \%$ das mulheres entrevistadas. As seguir vem a faixa etária com de 19 a 23 anos representando $5 \%$ e de menor ou igual a 15 anos representando $3 \%$.

Com relação ao local de residência a maioria, oito mulheres, mora na Asa Norte, cinco na Asa Sul; quatro em Taguatinga e quatro na Ceilândia, três no Guará, (2) em Planaltina, dois no Lago Norte e dois no Lago Sul. Nos demais locais houve apenas uma ocorrência: cidade Brazlândia, Vila Planalto, Novo Gama, Gama, São Sebastião, Águas lindas, Jardim Botânico.

Quanto à renda familiar constatou-se que na faixa de: mais de 10 salários mínimos estão nove mulheres; 7 a 10 salários mínimos sete mulheres; 4 a 6 salários mínimos nove mulheres; 2 a 3 salários mínimos sete mulheres; 1 salário mínimo cinco mulheres.

Com relação ao grau de escolaridade os dados mostram nesse universo que a maioria das mulheres (35\%) apresenta curso superior completo; (27\%) segundo grau completo; (14\%) segundo grau incompleto; (14\%) primeiro grau completo; (5\%) curso superior incompleto; (5 $\%)$ primeiro grau incompleto. Da amostra integraram mulheres com graduação em administração (2); arquitetura (1); biblioteconomia (4); ciências biológicas (1); letras (1); pedagogia (2); psicologia (1); relações internacionais (1); turismo (1).

Quanto a possuir algum tipo de curso profissionalizante constatou-se na amostra que 23 entrevistadas não fizeram nenhum tipo de curso profissionalizante. Entretanto, quatorze participaram de diversos cursos, tendo em alguns casos participado de mais de um curso profissionalizante.

Os cursos profissionalizantes foram os mais diversificados: contabilidade, gastronomia, desenho, copista, cabeleireira, magistério, administração de empresas, computação, informática, massagista, nutrição, química industrial, manicure, salgado e qualidade de atendimento.

Considerando o tipo de trabalho observa-se que $77 \%$ das mulheres trabalham fora de casa, apenas $8 \%$ não trabalham fora de casa, $10 \%$ estão desempregadas, $5 \%$ estão aposentadas. Esses dados confirmam as muitas estatísticas que identificam que a cada dia aumenta o número de mulheres que exercem uma profissão e até mesmo são provedoras de suas famílias. 
Com relação às necessidades e uso da informação foi elaborado o quadro 1 no qual foram compatibilizadas tanto as necessidades de informação quanto a freqüência de uso. Com relação à importância que os temas têm para a mulher e que podem ser indicadores dos temas possíveis para atender às necessidades de informação desse grupo foi identificado que mais de $80 \%$ considera da máxima importância a informação sobre saúde, mais de $70 \%$ sobre educação, transporte, trabalho, segurança, meio ambiente e ciência e tecnologia (C\&T) mais $60 \%$. Em torno de $40 \%$ usa frequentemente estes tipos de informação. Algumas entrevistadas comentaram que acham importante a informação sobre segurança, pois "vendo o que acontece toma mais cuidado". Quanto à C\&T uma entrevistada, que trabalha como empregada doméstica comentou que quer saber sobre o assunto para ajudar o filho sobre as novidades e citou os estudos das células tronco. Considera também muito importante a informação sobre meio ambiente, pois com essa informação ela alerta o filho quanto à necessidade de economizar água e energia "para ajudar o planeta".

QUADRO 1 - Necessidades de informação por área temática e frequência de uso

\begin{tabular}{|l|r|r|r|r|r|r|}
\hline \multirow{2}{*}{ Área temática } & \multicolumn{2}{|c|}{ Necessidade de Informação } & \multicolumn{2}{c|}{ Frequência de uso } \\
\cline { 2 - 7 } & Nenhuma & Pouca & Máxima & Nunca & Ocasional & Frequente \\
\hline Direitos do Cidadão & & & & & & \\
\hline Educação & $5,41 \%$ & $18,92 \%$ & $75,68 \%$ & $13,51 \%$ & $43,24 \%$ & $43,24 \%$ \\
\hline Saúde & $2,70 \%$ & $16,22 \%$ & $81,08 \%$ & $10,81 \%$ & $48,65 \%$ & $40,54 \%$ \\
\hline Habitação & $18,92 \%$ & $27,03 \%$ & $54,05 \%$ & $27,03 \%$ & $54,05 \%$ & $18,92 \%$ \\
\hline Transporte & $24,32 \%$ & $32,43 \%$ & $43,24 \%$ & $40,54 \%$ & $43,24 \%$ & $16,22 \%$ \\
\hline Trabalho & $10,81 \%$ & $13,51 \%$ & $75,68 \%$ & $18,92 \%$ & $32,43 \%$ & $48,65 \%$ \\
\hline Segurança & $10,81 \%$ & $10,81 \%$ & $78,38 \%$ & $18,92 \%$ & $40,54 \%$ & $40,54 \%$ \\
\hline Ciência e Tecnologia & $13,51 \%$ & $24,32 \%$ & $62,16 \%$ & $24,32 \%$ & $37,84 \%$ & $37,84 \%$ \\
\hline Meio ambiente & $16,22 \%$ & $8,11 \%$ & $75,68 \%$ & $27,03 \%$ & $27,03 \%$ & $45,95 \%$ \\
\hline Informação Utilitária & & & & & & \\
\hline Oportunidades emprego & $18,92 \%$ & $8,11 \%$ & $72,97 \%$ & $24,32 \%$ & $24,32 \%$ & $51,35 \%$ \\
\hline Cursos e locais de ensino & $5,41 \%$ & $18,92 \%$ & $75,68 \%$ & $5,41 \%$ & $35,14 \%$ & $59,46 \%$ \\
\hline Médicos e hospitais & $8,11 \%$ & $18,92 \%$ & $72,97 \%$ & $10,81 \%$ & $43,24 \%$ & $45,95 \%$ \\
\hline Financiamentos de casa & $43,24 \%$ & $5,41 \%$ & $51,35 \%$ & $54,05 \%$ & $18,92 \%$ & $27,03 \%$ \\
\hline Transportes oferecidos & $35,14 \%$ & $24,32 \%$ & $40,54 \%$ & $40,54 \%$ & $29,73 \%$ & $29,73 \%$ \\
\hline
\end{tabular}




\begin{tabular}{|c|c|c|c|c|c|c|}
\hline Primeiros Socorros & $35,14 \%$ & $27,03 \%$ & $37,84 \%$ & $48,65 \%$ & $35,14 \%$ & $16,22 \%$ \\
\hline Produtos de Primeira & & & & & & \\
\hline Necessidade & $16,22 \%$ & $21,62 \%$ & $62,16 \%$ & $21,62 \%$ & $32,43 \%$ & $45,95 \%$ \\
\hline Farmácias de Plantão & $40,54 \%$ & $24,32 \%$ & $35,14 \%$ & $43,24 \%$ & $43,24 \%$ & $13,51 \%$ \\
\hline Preços nos Supermercados & $13,51 \%$ & $10,81 \%$ & $75,68 \%$ & $18,92 \%$ & $18,92 \%$ & $62,16 \%$ \\
\hline \multicolumn{7}{|l|}{ Atualidades } \\
\hline Política & $27,03 \%$ & $18,92 \%$ & $54,05 \%$ & $40,54 \%$ & $16,22 \%$ & $43,24 \%$ \\
\hline Violência urbana & $10,81 \%$ & $13,51 \%$ & $75,68 \%$ & $13,51 \%$ & $29,73 \%$ & $56,76 \%$ \\
\hline Notícias econômicas & $35,14 \%$ & $37,84 \%$ & $27,03 \%$ & $40,54 \%$ & $40,54 \%$ & $18,92 \%$ \\
\hline Gênero - sobre a mulher & $8,11 \%$ & $13,51 \%$ & $78,38 \%$ & $8,11 \%$ & $29,73 \%$ & $62,16 \%$ \\
\hline \multicolumn{7}{|l|}{ Lazer } \\
\hline Esporte & $35,14 \%$ & $27,03 \%$ & $37,84 \%$ & $43,24 \%$ & $37,84 \%$ & $18,92 \%$ \\
\hline Artes & $18,92 \%$ & $35,14 \%$ & $45,95 \%$ & $32,43 \%$ & $32,43 \%$ & $35,14 \%$ \\
\hline Roteiros de Viagem & $27,03 \%$ & $27,03 \%$ & $45,95 \%$ & $29,73 \%$ & $43,24 \%$ & $27,03 \%$ \\
\hline Eventos culturais & $24,32 \%$ & $29,73 \%$ & $45,95 \%$ & $29,73 \%$ & $43,24 \%$ & $27,03 \%$ \\
\hline Restaurantes & $35,14 \%$ & $32,43 \%$ & $32,43 \%$ & $45,95 \%$ & $24,32 \%$ & $29,73 \%$ \\
\hline Cinema & $29,73 \%$ & $27,03 \%$ & $43,24 \%$ & $27,03 \%$ & $32,43 \%$ & $40,54 \%$ \\
\hline Música & $13,51 \%$ & $35,14 \%$ & $51,35 \%$ & $18,92 \%$ & $35,14 \%$ & $45,95 \%$ \\
\hline Dança & $21,62 \%$ & $35,14 \%$ & $43,24 \%$ & $35,14 \%$ & $40,54 \%$ & $24,32 \%$ \\
\hline Teatro & $32,43 \%$ & $27,03 \%$ & $40,54 \%$ & $43,24 \%$ & $32,43 \%$ & $24,32 \%$ \\
\hline Livros & $16,22 \%$ & $21,62 \%$ & $62,16 \%$ & $16,22 \%$ & $32,43 \%$ & $51,35 \%$ \\
\hline \multicolumn{7}{|l|}{ Crescimento pessoal } \\
\hline $\begin{array}{l}\text { Orientação Espiritual ou } \\
\text { Religiosa }\end{array}$ & $24,32 \%$ & $18,92 \%$ & $56,76 \%$ & $21,62 \%$ & $35,14 \%$ & $43,24 \%$ \\
\hline Orientação Psicológica & $24,32 \%$ & $24,32 \%$ & $48,65 \%$ & $40,54 \%$ & $32,43 \%$ & $27,03 \%$ \\
\hline
\end{tabular}

Fonte: elaboração própria

Comparando esses dados com os investigados por Nascimento (2003) as áreas de educação, saúde, segurança, ciência e tecnologia e meio ambiente também foram 
consideradas como de máxima importância por mais de $70 \%$ do grupo de mulheres que integraram seu estudo.

A informação sobre habitação e transporte foi considerada muito importante por mais de $40 \%$ das mulheres. As informações de caráter utilitário preços nos supermercados com $(75,68 \%)$ e oportunidades de empregos $(72,97 \%)$ lideram a lista de temas mais importantes desta categoria.

$\mathrm{Na}$ pesquisa de Nascimento (2003) as informações sobre necessidades de trabalho $(87,2)$ e transportes oferecidos $(67,1)$ lideraram a lista dos mais importantes. A informação sobre preços de supermercados $(57,1 \%)$ igualmente as de farmácia de plantão foram consideradas menos importantes do que as de transporte, primeiros socorros, produtos de primeira necessidade. Já neste estudo a informação sobre farmácias de plantão $(35,14 \%)$, seguida de transportes oferecidos $(40,57 \%)$ foram consideradas menos importantes que as outras.

Quanto à informação sobre médicos e hospitais uma entrevistada disse achar muito importante "mas dava graças a Deus nunca precisar", outras com idade acima de 50 anos afirmaram ser de grande importância e que necessitavam com frequência.

Com relação ao tema atualidades, a informação sobre o gênero mulher, lidera esta lista de importância com $(78,38 \%)$ seguida do tema violência urbana com $(75,68 \%)$. Os temas como política são os que tiveram, nesta categoria, menor grau de importância $(54,05 \%)$ e notícias econômicas somente $(27,03)$, devido à complexidade e necessidade de outros conhecimentos para o seu entendimento, no caso de informações econômicas e de informação sobre política destacaram o problema pelo qual o país está passando em que as instituições políticas e seus respectivos produtos estão desacreditados.

No resultado do trabalho do Nascimento (2003) os temas política $(91,4 \%)$ e gênero mulher $(87,2 \%)$ também lideram este grupo de temas, seguidos de violência urbana $(81,4 \%)$ e notícias econômicas $(80,0 \%)$.

Quanto à informação de lazer, os livros $(62,16 \%)$, música $(51,35 \%)$ estão no topo da lista das mais importantes, vindo logo depois artes, roteiro de viagem e eventos culturais (cada uma com 45,95\%). Cinema e dança vem em seguida $(43,24 \%)$ e teatro com $(40,54 \%)$. Esporte $(37,84)$ e restaurante $(32,43 \%)$ foram, nesta categoria, os temas de menor importância. Na pesquisa de Nascimento (2003), os temas artes (70\%) eventos culturais $(68,5 \%)$ esportes $(62,9 \%)$ foram os mais importantes.

Neste estudo as informações sobre orientação espiritual ou religiosa foram consideradas muito importantes para $(56,76 \%)$ e orientação psicológica $(48,65 \%)$. No estudo de Nascimento a orientação espiritual ou religiosa $(45,7 \%)$ e orientação psicológica $(44,3 \%)$. 
De todos os temas, os que apresentam o menor percentual no nível de importância máxima foram as informações referentes a notícias econômicas (27,03\%), restaurantes $(32,43)$, farmácias de plantão $(35,14 \%)$, primeiros socorros e esporte $(37,84 \%)$.

Com relação às fontes de informação utilizadas foram realizadas diversas perguntas. Quanto à leitura de jornais a maioria, 57\%, lê jornal frequentemente, $32 \%$ lê raramente e 11\% nunca leem. Quanto aos títulos de jornais mais lidos diversos títulos receberam apenas uma indicação tais como: O Globo, Na Hora, Estado de Minas, O Lutador, Opinião, Observatório Romano e Super Noticia. Os demais receberam mais de uma: Jornal de Brasília - 2; Jornal da Comunidade - 4; Folha de S. Paulo - 3; e Correio Braziliense - 25.

Quanto à utilização de revistas como fonte de informação a grande maioria, 67\% informou que lê algum tipo de revista, 22\% lê raramente e $11 \%$ não lê revistas. Da mesma forma que os títulos de jornais, foram indicados diversos títulos diferentes. Citados apenas uma vez: revistas de artesanato, Flash, Carta Capital, Contigo, Casa Cláudia, Gula, Dietas Já, Amigos, revistas de fofocas, Marie Claire, Psique, Criativa e National Geographic. Apenas a revista Super Interessante foi citada - 2 vezes. Revista Cláudia -3, Revista Época 4, Revista Caras - 6, Isto é - 6 e Revista Veja - 13.

Quanto às mídias utilizadas como fonte de informação a televisão e o rádio ocuparam lugar de destaque como fonte de utilização diária: a televisão com quase $70 \%$; rádio com mais de $45 \%$; o computador com $40 \%$; TV a cabo com $20 \%$.

Quanto ao uso da Internet a grande maioria (70\%) afirmou que a utiliza. Com relação ao local de acesso à Internet e a sua frequência, foram detectados que pelo menos $50 \%$ das mulheres usam a Internet com uma frequência diária de casa e do local de trabalho. Mais de $60 \%$ não nunca fazem uso da Internet em casa de amigos, lan house, biblioteca sendo que esta última $80 \%$ não usam este local.

Quanto às fontes utilizadas para busca de informação a mais utilizada é a internet seguida do jornal, televisão, rádio, pessoas, sindicato, biblioteca da escola, biblioteca publica e Igreja.

Quanto às dificuldades enfrentadas pelas mulheres para encontrar a informação que necessitam foi identificado: a maioria de 14 mulheres encontrou a fonte, mas a burocracia não permitiu chegar a informação; 12,5 mulheres tiveram dificuldades de acesso para localizar a informação; 12 não encontraram por ausência de pessoal para informar; 10,5 tem desconhecimento da fonte de informação e encontra muita informação mas não atende as necessidades; oito têm dificuldade pois a pergunta que fazem não é entendida; 4,5 não encontra nenhuma dificuldade. 


\section{CONCLUSÕES}

O trabalho de identificação das necessidades de informação das mulheres no DF mostrou que quase a metade das mulheres entrevistadas tem uma renda de sete a mais de 10 salários mínimos. Todas são alfabetizadas e $35 \%$ possuem curso superior e $27 \%$ o segundo grau completo. Neste sentido vale ressaltar que resultados do mapa do MEC (s.d) no Brasil mostram que o analfabetismo entre as mulheres é praticamente igual aos dos homens com respectivamente $12,3 \%$ e $12,4 \%$, ambos na faixa de 15 anos.

Os resultados do trabalho revelaram também que $77 \%$ das mulheres, portanto a grande maioria trabalha fora de casa, o que confirma as muitas estatísticas que afirmam que a cada dia aumenta o número de mulheres que exercem uma profissão e, até mesmo são provedoras de suas famílias.

O estudo mostrou, ainda, que os temas sobre saúde é um dos que tem a maior importância seguido de educação, trabalho, segurança, e meio ambiente ciência e tecnologia (C\&T). As informações de preços nos supermercados e oportunidades de empregos lideram a lista de temas importantes na categoria informação utilitária.

$\mathrm{Na}$ categoria de informação atualidades o gênero mulher destaca-se como tema mais importante, seguido do tema violência urbana. O tema política não foi considerado tão importante, mas pelos menos a metade se interessa.

Quanto à informação ligada ao lazer, os livros e música estão no topo da lista dos mais importantes. Artes, roteiros de viagem e eventos culturais são considerados menos importantes, mas ainda ocupam um lugar significativo em torno de $40 \%$ que desejam esta informação. A orientação espiritual ou religiosa e psicológica também são temas considerados importantes pelos menos por metade do grupo.

Em relação às fontes de informação utilizadas a maioria dá preferência à leitura de jornais e utiliza a televisão e o rádio diariamente. A Internet é usada diariamente, pelo menos, pela metade desse grupo. No entanto, ainda é pouco. É necessário que mulher possa usar todo o potencial da informação por meio das novas tecnologias para seu crescimento como ser político, social e humano. Nesta linha, a constatação de grupos feministas que participam da Cúpula Mundial da Sociedade da Informação, na Tunísia, alertam que as novas tecnologias de informação e comunicação, TICs, estão contribuindo para aumentar ainda mais a desigualdade entre homens e mulheres.

Esses grupos feministas argumentaram que não se trata apenas de falta de acesso à Internet. "O problema é que as mulheres não estão se envolvendo com tecnologia e estão ficando para trás em um campo cheio de oportunidades econômicas, sociais e culturais", afirma a ativista filipina Chat Garcia Ramilo, coordenadora da organização não governamental internacional Programa de Apoio a Redes de Mulheres. O movimento de mulheres vem fazendo campanhas, nos últimos anos, por uma maior participação feminina em funções técnicas - como desenvolvimento de programas de computadores e design de 
websites - e pela ascensão das mulheres a postos de liderança no setor. Depois de grande esforço de convencimento diplomático, as ativistas conseguiram que a declaração final da Cúpula Mundial da Sociedade da Informação na Tunísia incluísse a necessidade dos países desenvolverem a capacitação e a autoconfiança das mulheres (DETONI, 2007).

Dentre as fontes mais utilizadas para busca de informação foram identificadas também a Biblioteca do CEUB, do IESB, do Ministério da Justiça, da UnB, do SESC, sendo estas três últimas consideradas para efeito quantitativo como bibliotecas públicas, uma vez que estão abertas ao público de maneira geral, apesar de serem consideradas como bibliotecas especializadas e universitárias.

Quanto às dificuldades enfrentadas pelas mulheres para encontrar a informação que necessitam, a maior foi encontrar a fonte porque a burocracia não permitiu chegar à informação; as dificuldades de acesso para localizar a informação e ausência de pessoal para informar foram outras dificuldades encontradas.

Quanto à metodologia aplicada tem-se a considerar que devido à pouca quantidade de estudos de necessidades de informação sobre a mulher, entende-se que se faz necessário a utilização de metodologias exploratórias de forma a tentar identificar os tipos de informação que são demandados pela mulher, e a partir desse levantamento exaustivo, aplicar então estudos quantitativos, com vistas a tentar prever comportamentos e necessidades de informação.

Merece destacar um fato percebido pelas entrevistadoras durante o processo de coleta de dados. Refere-se ao fato de que as necessidades de informação estão relacionadas ao momento de vida, à idade da pessoa, entretanto, devido às limitações deste estudo não foi possível o cruzamento de dados. Exemplificando melhor: as pessoas mais jovens estavam mais preocupadas com emprego, o que já não acontecia com as aposentadas; semelhante ocorreu em relação ao interesse por imóveis e condições de financiamento, uma vez que as pessoas que já tinham sua vida estabilizada não se interessavam mais por esses itens.

Outro ponto interessante refere-se às pessoas considerarem filmes, teatro, restaurantes e demais atividades culturais como importantes, porém não faziam uso frequente, e quando questionadas argumentaram falta de recursos financeiros, pois consiste em um tipo de atividade não muito popular.

Estudos de identificação das necessidades das mulheres podem ser muitos úteis para conhecer não só as necessidades de informação das mulheres, mas também para mostrar suas dificuldades de acesso e localização da informação, bem como lidar com as novas tecnologias e sugerir serviços de informação adequados a sua realidade.

A Ciência da Informação e Biblioteconomia

[...] precisam atentar para a diversidade dos grupos sociais e utilizar metodologias de outras áreas e construir um instrumental adequado à sua prática que possibilite 
desenhar um perfil mais próximo do sujeito-mulher. Abordar a mulher como sujeito do processo significa tratá-la dentro de uma dada população e observar sua diversidade no grupo mulher. Pode significar uma contribuição da área para que ocorra uma redefinição do papel da mulher em termos de oportunidades e recursos [...](EGGERT 1992, p.100).

\section{REFERÊNCIAS}

BAPTISTA, Sofia Galvão; CUNHA, Murilo Bastos. Estudos de usuários: visão global do método de coletas de dados. Perspectiva em Ciência da informação, v. 12, n. 2, p.168184, 2007.

BORGMAN, C. A premissa e promessa de uma infra-estrutura global de informação. Revista de Biblioteconomia de Brasília, v. 25, n. 1, p. 77-90, jan./jun., 2001.

BRASIL. Ministério da Educação. Mapa do Analfabetismo no Brasil. Brasília: Instituto Brasileiro de Pesquisas Educacionais. [s.d.]

ComCiência. Mulheres na Ciência. 2003. Disponível em: $<$ http://www.comciencia.br/ reportagens/mulheres/03.shtml>. Acesso em: 03 out. 2007.

DETONI, Márcia. Novas tecnologias aumentam desigualdade entre homens e mulheres, alertam feministas. Disponível em: 〈http://www.radiobras.gov.br/materia_i_2004.php?

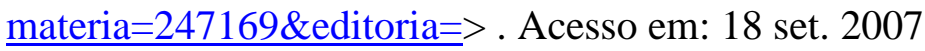

EGGERT, Gisela. Fontes de informação e a questão de gênero no cotidiano da mulher (dona de casa). Revista da Escola de Biblioteconomia, UFMG, v. 23, n. 2, p. 167-188, jul./dez., 1994.

EGGERT, Gisela. A informação no cotidiano do sujeito - mulher feminino. 117f. 1992. Dissertação (Mestrado em Ciência da Informação) Escola de Biblioteconomia. Universidade Federal de Minas Gerais. Belo Horizonte. 1992.

FAIRER-WESSELS, F. Basic community information needs of urban women in Mamelodi, Pretoria, South Africa. South African Journal of Library and Information Science, v. 58, n. 4, p. 359-369, Dec, 1990.

FOSTER, G. Information empowerment: Will women in the personal social services get look in?.Assignation, v. 15, n. 3, p. 3-4, Apr, 1998.

GLASS, Betty. Information needs of minority women as serial resources: a selected bibliography. Reference Librarian, v. 27/28, p. 289-303, 1990. 
GUNDARA, J. Indian women: information needs. London, Polytechnic of North London School of Librarianship, 1981.

HEIJS, M. Subject searching in strange libraries - a challenge: with a bit more knowledge of the subject area it could have been arranged better. Bibliotheek en Samenleving, v. 18, n. 10, Oct 1990. Special issue on women's information services.

HUBER, J.; CRUZ, J. Information needs and information-seeking behaviors of HIV positive men and women. Medical Reference Services quarterly, v. 19, n. 3, p. 39-48, Fall, 2000.

IKOJA-ODONGO, J. Insights into the information needs of women in the informal sector of Uganda. South African Journal of Library and Information Science, v. 68, n. 1, p. 39-52, 2002.

KIONDO, Elizabeth. Access to gender and development information by rural women in Tanzania. Innovation, v. 19, p. 18-27, Dec, 1999.

LIMA, Justino Alves. Comunidades carentes, lugares da não informação. 2006. 164 f. Tese (Doutorado em Ciência da Informação) - Escola de Comunicação da Universidade de São Paulo. São Paulo, 2006.

LOURO, G. L. Nas redes do conceito de gênero. In: LOPES, Marta J. M.; MEYER, D.; WALDOW, V. R. (Org.). Gênero e saúde. Porto Alegre: Artes Médicas, 1996. p. 7-18.

MABAWONKU, I. The information environment of women in Nigeria's public service. Journal of Documentation, v. 62, n. 1, p. 73-90, 2006.

MARCELLA, R. The need for European Union Information amongst women in the United Kingdom: results of a survey. Journal of Documentation, v. 57, n. 4, p. 492-518, Jul., 2001.

MINAYO, M. C de S.; SANCHES, O. Quantitativo-qualitativo: oposição ou complementaridade? Caderno de Saúde Pública v. 9, n. 3. 1993. Disponível em : <http://www.scielo.br/scielo.php?script=sci_arttext\&pid=S0102-311X1993000300002\&lng $=$ en\&nrm=iso $>$. Acesso em: 15 nov. 2007

MOOKO, Neo Patricia. The information behaviors of rural women in Botswana. Library and Information Science Research, v. 27, n. 1, p. 115-127, 2005.

NASCIMENTO, Maria de Jesus. Informação e cidadania: necessidades e formas de busca por parte da mulher catarinense. Informação e Sociedade, v. 13, n. 2, 2003. Disponível em: <http://www.ies.ufpb.br/ojs2/index.php/ies/article/view/94/90>. Acesso em: 20 set. 2007 
NWAGHA, Georgiana K. Information needs of rural women in Nigeria. Information Development, v. 8, n. 2, p. 76-82, Apr., 1992.

O ACESSO à informação promove o envolvimento das mulheres na política. Disponível em: <http://www.article19.org/work/regions/latin-america/FOI/portugues/arguments/index.html $>$. Acesso em: 18 set. 2007.

OLADOKUN, S.O. An empirical study of information needs of women in agriculture (WIA) in Oyo State, Nigeria. Quarterly Bulletin of the International Association of Agricultural Inf. Specialist, v. 39, n. 4, p. 319-323, 1994.

VAN WESTRUM, K; SCHADE, K. N. What public libraries have to offer: collection building in the field of women's information. Bibliottheek en Samenleving, v.18, n. 10, Oct. 1990. Special issue on women's information services.

SILVA, J. F.; FERREIRA, M. A. T.; BORGES, M. E. N. Análise metodológica dos estudos de necessidades de informação sobre setores industriais brasileiros: proposições. Ciência da Informação, v. 31, n. 2, p. 129-141, 2002.

SIMIONI, Fabiane. As desigualdades de gênero e o novo Código Civil. ComCiência. Mulheres na Ciência. 2003. Disponível em: 〈http://www.comciencia.br/reportagens/ mulheres/11.shtml>. Acesso em: 03 out. 2007.

SOIHET, Rachel. História das mulheres e relações de gênero: debatendo algumas questões. Com Ciência. Mulheres na Ciência, 2003. Disponível em: <http://www.comciencia.br/ reportagens/mulheres/16.shtml>. Acesso em: 01 out. 2007.

STOKES, Peter. Information services for the voluntary sector- what public libraries. Public Library Journal, v. 2, n. 1, p. 1-4, Jan./Feb., 1987.

STUMPF, Ida Regina C. Usuário da Informação no contexto digital. II SEMINÁRIO da Ciência da Informação. Londrina, 27 a 20 de 2007. Disponível em: <http://www.uel.br/ceca/ cinf/eventos/seminario/apresentacoes/arquivos/ISTUMPF_Usuario_Informacao_Digital.pdf> . Acesso em: 16 nov. 2007

VELHO, Lea; PROCHAZKA, Maria Vivianna. No que o mundo da ciência difere dos outros mundos? Com Ciência. Mulheres na Ciência. 2003. Disponível em: <http://www.comciencia .br/reportagens/mulheres/09.shtml>. Acesso em: 11 out. 2007.

WANG, Peiling. Methodologies and methods for user behavioral research. Annual Review of Information Science and Technology (ARIST), v. 34, p. 53-99, 1999.

WHITT, A. The information needs of lesbians. Library and Information Science Research, v.15, n. 3, p. 275-288, Summer, 1993. 
WILSON, T. D. Revisiting user studies and information needs. Journal of documentation, v. 62 , n. 6, p. 680-684, 2006.

Como citar este documento:

CARIBÉ, Rita de Cássia do Vale; PINTO, Alejandra Aguilar; DIOGENES, Fabiene Castelo Branco. Necessidades de informação do Gênero Mulher no Distrito Federal, Brasil: resultado de um survey. Revista Digital de Biblioteconomia e Ciência da Informação, Campinas, SP, v. 13, n. 2, p. 418-436, maio/ago. 2015. ISSN 1678-765X. Disponível em:

<http://periodicos.bc.unicamp.br/ojs/index.php/rdbci/article/view/8635039>. Acesso em: 31 maio 2015. 